\title{
MELHORIA NO DESEMPENHO DOS CLASSIFICADORES ESPIRAIS UTILIZADOS NO PROCESSO DE BENEFICIAMENTO DE MINÉRIO DE FERRO*
}

\author{
Cristiano Simplício Guimarães de Almeida ${ }^{1}$ \\ Edilberto da Silva Souza ${ }^{2}$ \\ José Dimas de Arruda ${ }^{2}$ \\ Alexandre Magno Franco Ferreira ${ }^{2}$ \\ Alfredo Ganime Junior ${ }^{2}$ \\ Nilo Antunes Ferreira ${ }^{2}$
}

\section{Resumo}

Este trabalho teve como objetivo melhorar o baixo desempenho apresentado em classificadores espirais do processo de beneficiamento mineral. Fez-se necessário uma análise das causas das manutenções corretivas nos mancais submersos e espiras para melhorar a disponibilidade física (DF). Foi realizado um brainstorming para relacionar as causas mais prováveis, utilizando o sistema de controle informatizado das manutenções corretivas, locais e duração para sua execução. Após o registro das causas do baixo desempenho, foi elaborado um plano de ação para eliminar as não conformidades do processo, implementando melhorias através da Metodologia de Análise e Solução de Problemas (MASP), verificando uma melhora no desempenho dos mancais submersos e espiras dos classificadores, aumentando a disponibilidade física e vida útil de seus componentes.

Palavras-chave: Mancal Submerso; Manutenção Corretiva. Classificadores Espirais.

\section{IMPROVEMENT IN THE PERFORMANCE OF THE SPIRAL CLASSIFIERS USED IN THE IRON ORE BENEFIT PROCESS}

\begin{abstract}
This work aimed to improve the low performance presented in spiral classifiers of the mineral processing process. It was necessary to analyze the causes of corrective maintenance in the submerged bearings and turns to improve the physical availability (DF). A brainstorming was performed to relate the most probable causes, using the computerized control system of corrective maintenance, locations and duration for its execution. After recording the causes of low performance, a plan of action was elaborated to eliminate the nonconformities of the process, implementing improvements through the Methodology of Analysis and Problem Solving (MASP), verifying an improvement in the performance of the submersible bearings and turns of the classifiers, Increasing the physical availability and life of its components.
\end{abstract}

Keywords: Submerged Bearing; Corrective maintenance. Spiral Classifiers.

1 Graduando em Engenharia Mecânica, Fundação Presidente Antônio Carlos, Conselheiro Lafaiete, Minas Gerais, Brasil.

2 Engenheiro, Mestre, Professor da Fundação Presidente Antônio Carlos, Conselheiro Lafaiete, Minas Gerais, Brasil.

3 Engenheiro, Professor da Fundação Presidente Antônio Carlos, Conselheiro Lafaiete, Minas Gerais, Brasil.. 


\section{INTRODUÇÃO}

A mineração de ferro no Brasil começou com o processamento e utilização das hematitas (minério rico em ferro). Os processos de tratamento deste mineral até a década de 70 contemplavam apenas britagem, classificação, empilhamento e transporte (Curso de Mineração Básico - Vale, 2014).

Porém o mundo começou a demandar produtos mais elaborados em granulometria, teor de ferro contido, controle de contaminantes, baixo teor de sílica, dentre outros.

O beneficiamento mineral por via úmida demanda a separação bem definida dos finos objetivando dois tipos de matéria prima, a saber: Pellet Feed e Sinter Feed, para alimentações de usinas de pelotização e sinterização, respectivamente (Curso de Mineração Básico - Vale, 2014).

Conforme Chaves (2012), os equipamentos mais competitivos e eficientes da década de 70 , para partição primária destas massas para direcionamento dos produtos, foram os classificadores espirais, que consistiam de uma piscina (pool) que era alimentada por polpa de minério, uma rosca de Arquimedes (simplex) ou duas (duplex), de uma ou duas entradas.

As hélices destas máquinas eram revestidas por placas de ferro fundido branco ligado. Uma das pontas do eixo que suportava estas hélices ficava submersa dentro da piscina apoiada num mancal, conhecido como mancal submerso do classificador espiral.

Os problemas com a vida útil dos rolamentos e vedações dos mancais submersos, baixa vida útil das placas de desgastes das hélices, e as centenas de parafusos de fixação das mesmas que frequentemente se soltavam e provocavam acidentes que empenavam estas hélices e seus braços suportes, criaram uma imagem de baixa confiabilidade e baixa disponibilidade física destas máquinas.

Surgiu no mercado de beneficiamento mineral uma máquina que atraiu o interesse dos engenheiros, a peneira de ressonância fabricada pela Derrick originária dos USA. O número de peneiras para substituir um classificador espiral de diâmetro da rosca de 84 polegadas era enorme, apesar das peneiras não terem os problemas do classificador espiral, ocupava uma área muito maior nas usinas e com amostragens mais complexas.

As peneiras de ressonância foram introduzidas na década de 90 e predominam até hoje, pelo simples fato dos nossos engenheiros terem parado as pesquisas de desenvolvimento dos classificadores espirais (ALBUQUERQUE, 2009).

Como a planta de classificação da mineração é da década de 80 , os classificadores espirais permaneceram no processo, apesar do tempo médio entre falhas, MTBF, ser extremamente baixo.

\subsection{Beneficiamento de minérios}

Normalmente, os minerais não são encontrados na natureza na forma e composição a serem utilizados pela indústria, seja na sua granulometria ou pelas "impurezas" associadas. Justamente para a adequação destes minerais, são empregados o beneficiamento dos minérios.

Tratamento ou beneficiamento de minérios são todas as atividades no processo de mineração que modifica a granulometria e/ou concentração do minério, sem modificar a identidade física do mesmo (FRANÇA, 2010).

Segundo a NRM-18, "entende-se por beneficiamento de minérios o tratamento visando preparar granulometricamente, concentrar ou purificar minérios por métodos físicos ou químicos sem alteração da constituição química dos minerais". O autor afirma também que o beneficiamento de minério pode ser realizado em 5 etapas: 
Cominuição (Britagem e Moagem): operação que visa a quebra e a redução de tamanho dos blocos ou partículas e é realizada pelos britadores e moinhos (VARELA, 2011).

Peneiramento e classificação: processos que consistem em separar as partículas de acordo com as dimensões físicas desta. É realizada pelas peneiras, ciclones e classificadores espirais.

Concentração: é o processo de separação do bem mineral com valor econômico do rejeito, realizado através dos concentradores em tambor e células de flotação.

Desaguamento: processo destinado a retirada da água para poder se obter produtos com baixa umidade, realizado através de espessadores e filtro de tambor.

Os resíduos do processo são transportados para as barragens de rejeitos. A Figura 1 demonstra o fluxograma do tratamento de minério desde a chegada do material lavrado, até a obtenção do mineral e a deposição da ganga em barragens de rejeitos.

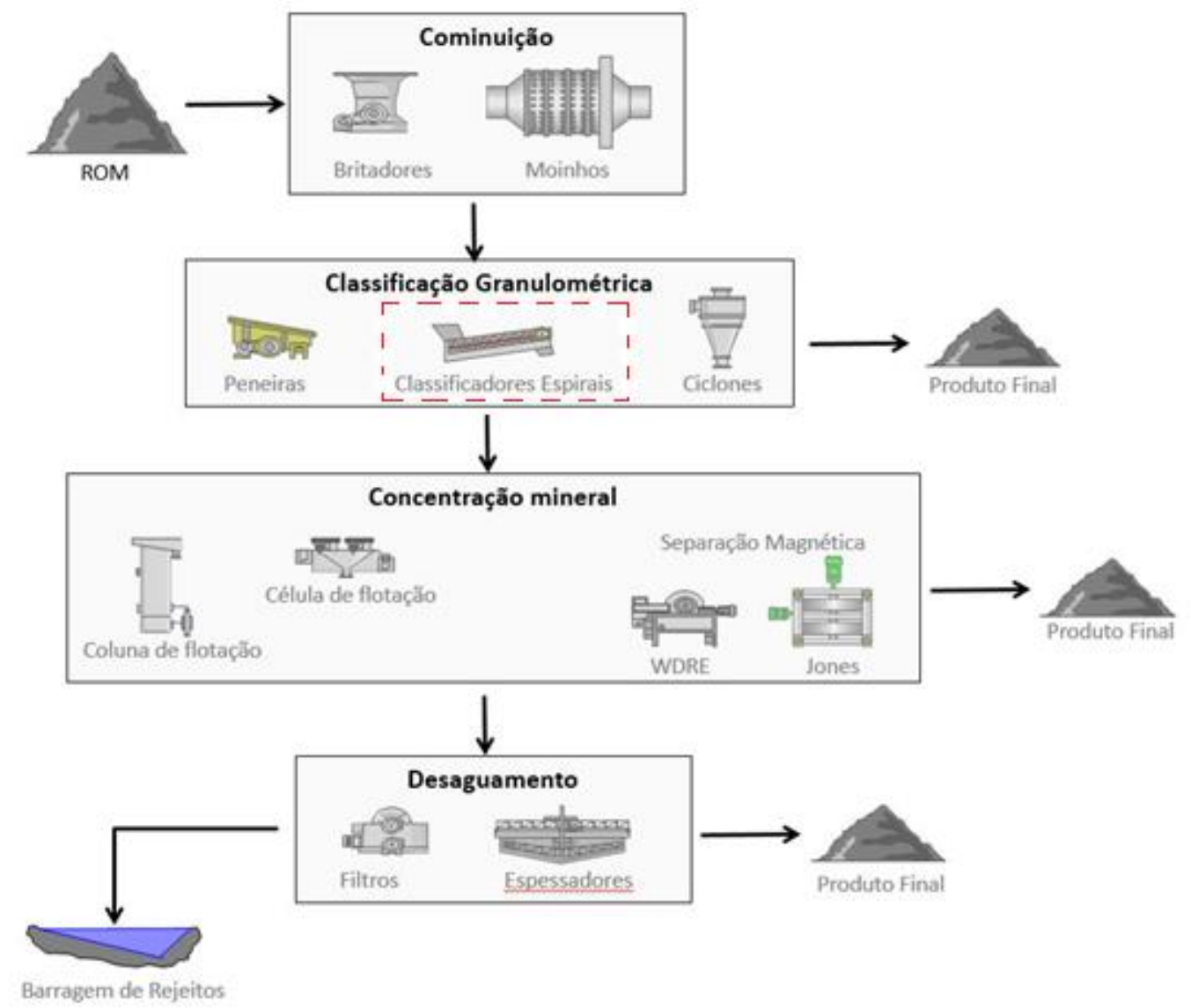

Figura 1 - Fluxograma do circuito de mineração destacando os classificadores espirais (Curso de Mineração Básico - Vale, 2014).

O mineral lavrado é depositado em uma pilha, que alimenta o circuito de cominuição onde é realizada a fragmentação das rochas, e este por sua vez é classificado em dois estágios de peneiramento, onde se obtém o retido que é o primeiro estágio e retorna no circuito até virar passante, que é o segundo estágio. Nesse segundo estágio o passante é enviado ao classificador espiral. A partir deste momento o equipamento alvo deste estudo, classificador espiral, é alimentado com as partículas passantes $(<2,0 \mathrm{~mm})$, já as partículas grosseiras retidas $(>2,0 \mathrm{~mm})$ no peneiramento são rebritadas em circuito fechado. 


\subsection{Classificadores Espirais}

Classificadores Espirais são equipamentos empregados para a separação de minerais, baseado no movimento relativo dos grãos através de um meio fluído, gerando dois produtos, um fino e outro grosseiro. Constitui uma bacia de sedimentação em que as partículas finas saem por transbordo, overflow, e as partículas grossas são removidas do fundo, underflow, por arraste mecânico. (CHAVES, 2012).

A Figura 2 mostra o classificador espiral que consiste, basicamente, de um tanque inclinado contendo um parafuso sem fim (espirais) que gira em seu eixo central.

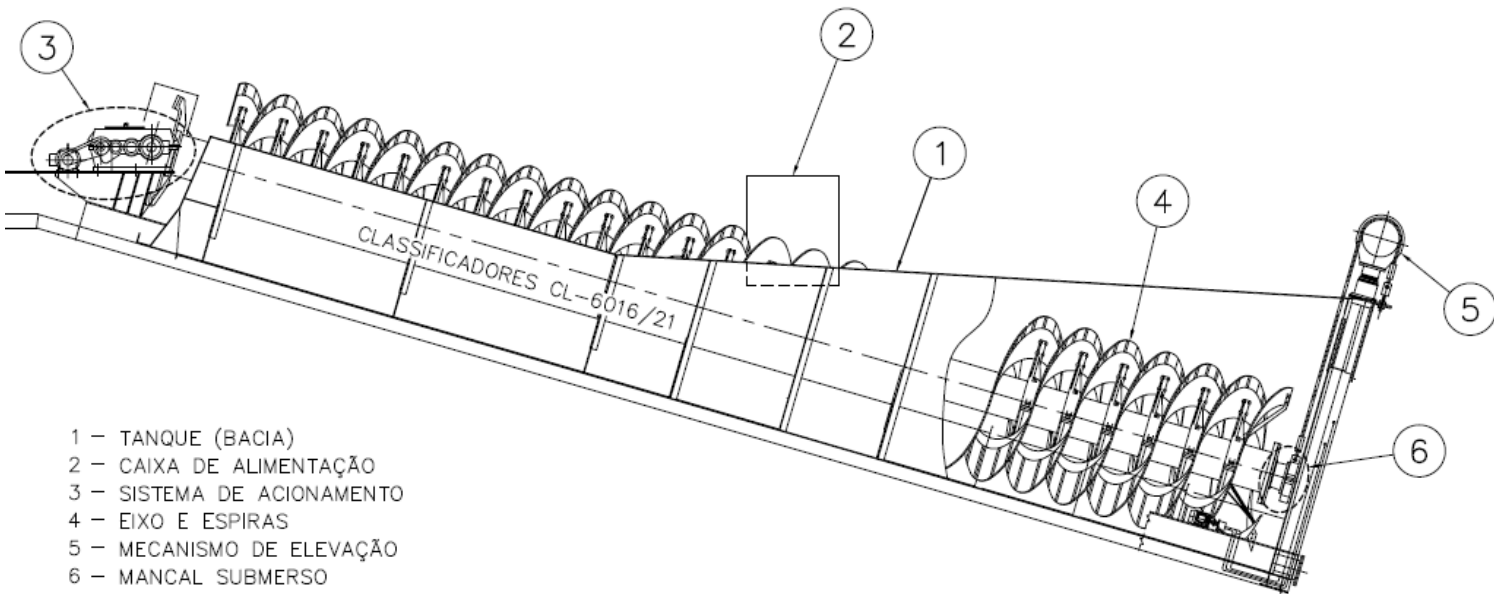

Figura 2 - Desenho esquemático do classificador espiral (Curso de Mineração Básico - Vale, 2014).

De acordo com Carrisso (2004), classificador espiral é uma calha que traz em seu interior um eixo envolto por hélices que ao girar conserva a polpa em suspensão. A finalidade dessas hélices é remover o material depositado do fundo da calha.

Metso (2012) afirma que o classificador espiral é a combinação de um decantador de gravidade de seção retangular com uma espiral inclinada para transporte do sedimentado. O classificador espiral é um equipamento de confiança para trabalhos pesados de classificação na faixa de 100-1000 micrometros. Possui uma configuração simples e robusta com poucas partes móveis. É um equipamento que possui muitas aplicações práticas no beneficiamento de minérios. A Figura 3 mostra a caixa de alimentação de um classificador industrial.

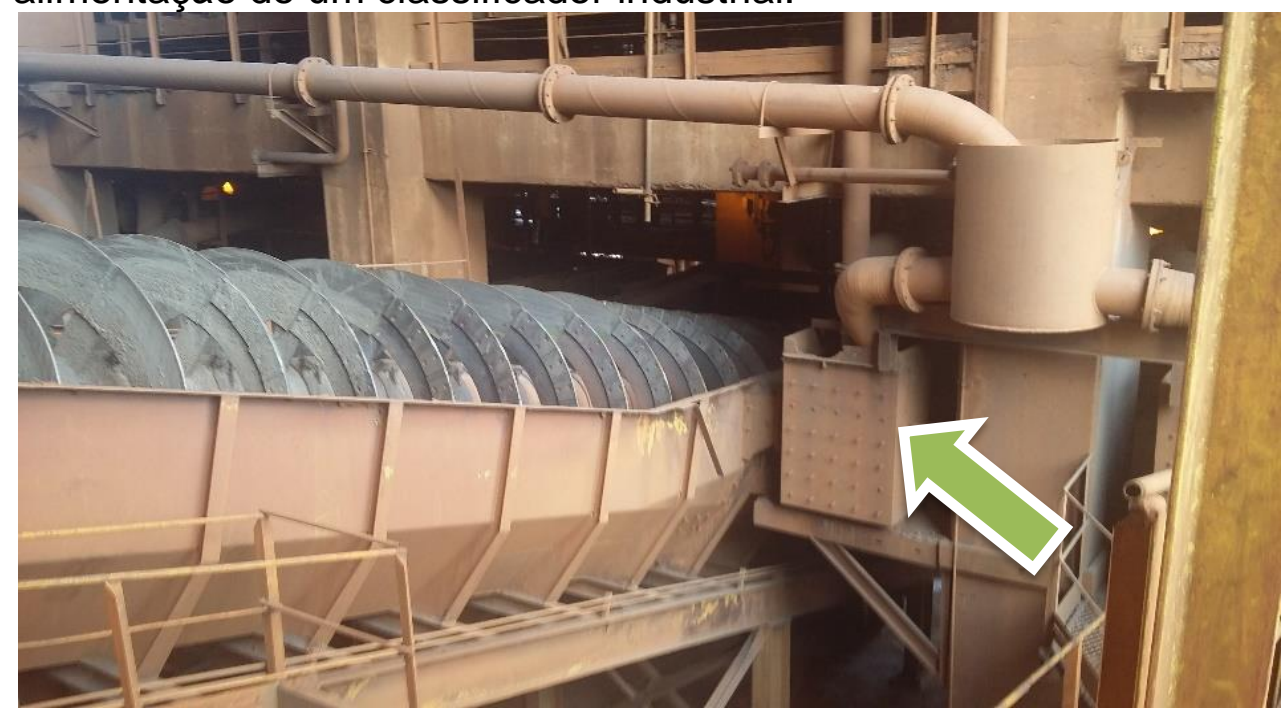

Figura 3 - Detalhe da caixa de alimentação no classificador espiral (Curso de Mineração Básico - Vale, 2014). 
O método de classificação por espiral consiste em receber a polpa do mineral em meio denso, para realizar a separação das partículas grosseiras $(<2,0 \mathrm{~mm}>$ $0,15 \mathrm{~mm})$, originando o underflow, das partículas finas $(<0,15 \mathrm{~mm})$, que seguem 0 fluxo da água com o auxílio gravitacional, indo de encontro à bacia inferior do equipamento, gerando o overflow, através da rotação das espiras em contato com a polpa. O objetivo fundamental é classificar a úmido as frações que irão compor o Sínter Feed e o Pellet Feed.

O produto do underflow é denominado Sínter Feed $(>0,15 \mathrm{~mm}<2,0 \mathrm{~mm})$, que alimenta os separadores magnéticos de tambores, de média intensidade. O produto do overflow resulta o Pellet Feed $(<0,15 \mathrm{~mm})$ que segue para o processo de deslamagem utilizando ciclones e posteriormente é concentrado em células e colunas de flotação.

O processo dos classificadores espirais é uma etapa do beneficiamento de minérios que utiliza diferenças entre as densidades das partículas presentes na polpa para promover a separação, explorando o efeito de sedimentação por gravidade.

O classificador espiral é muito importante para o alcance das especificações dos produtos finais. A deficiência nesta etapa provoca a contaminação dos produtos Sínter Feed e Pellet Feed e reduz a recuperação mássica. Produtos fora de especificações geram insatisfação no cliente, além de acarretar multas pelo não cumprimento dos contratos.

É necessária manutenção preventiva, planejada e controlada, realizada em datas predeterminadas, para manter a máquina ou equipamento em correta condições de funcionamento e conservação, evitando paradas imprevistas. (ALMEIDA, 2014).

Segundo Pereira (2011), a disponibilidade física (DF) "representa o tempo entre a abertura de um chamado de reparo para manutenção até sua liberação para retornar à operação".

\section{MATERIAIS E MÉTODOS}

Os equipamentos de estudo são os classificadores espirais, que compõe o circuito de classificação granulométrica do beneficiamento de minério.

Realizou-se uma coleta de dados de forma quantitativa em sistema informatizado de controle de eventos de paradas de manutenção das instalações. Os dados foram extraídos entre setembro de 2014 e setembro de 2015, com acompanhamento do perfil de perdas, verificando e estratificando os defeitos que mais impactaram no desempenho do equipamento.

A Metodologia de Análise e Solução de Problemas (MASP) foram utilizadas para auxiliar no desenvolvimento da melhoria contínua, com o objetivo de resolução dos problemas e otimização dos resultados.

Foram constatados vários eventos relacionados à quebra do mancal submerso dos classificadores, totalizando mais de 90 horas, sendo que esses dados são somente de manutenção corretiva, desconsiderando as trocas em manutenção periódica (preventiva) que ocorrem a cada três meses neste equipamento, com a substituição do mancal submerso. Mesmo com este curto período entre as trocas, existe a ocorrência de manutenção corretiva oriunda das quebras dos mancais, culminando em uma baixa disponibilidade física.

O mancal inferior do classificador espiral é projetado para trabalhar com lubrificação a graxa, como este fica na parte inferior do equipamento, que fica imerso em água, Figura $4 \mathrm{a}$, seu funcionamento é prejudicado com resíduo de minério de ferro. A Figura $4 \mathrm{~b}$ mostra os danos aos rolamentos e mancal submerso devido a contaminação do lubrificante. 
a)

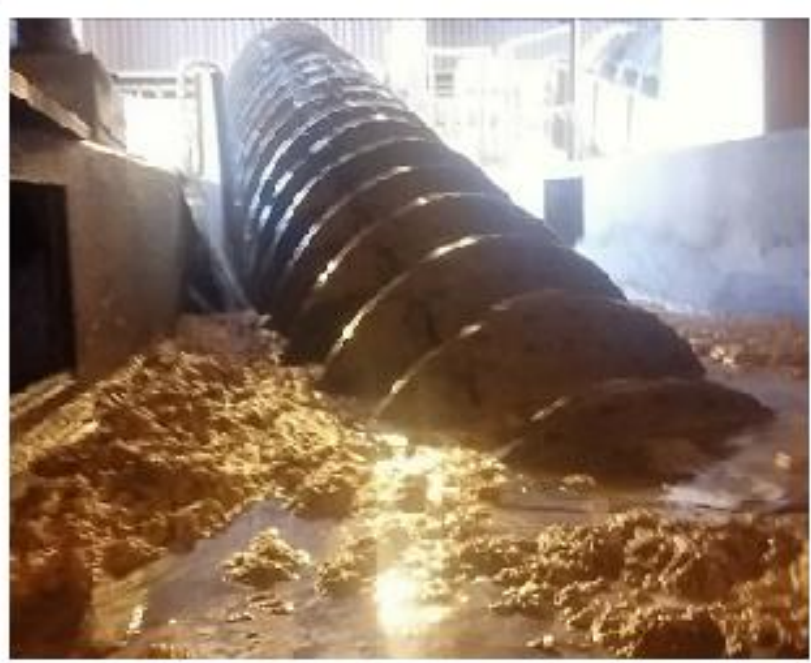

b)

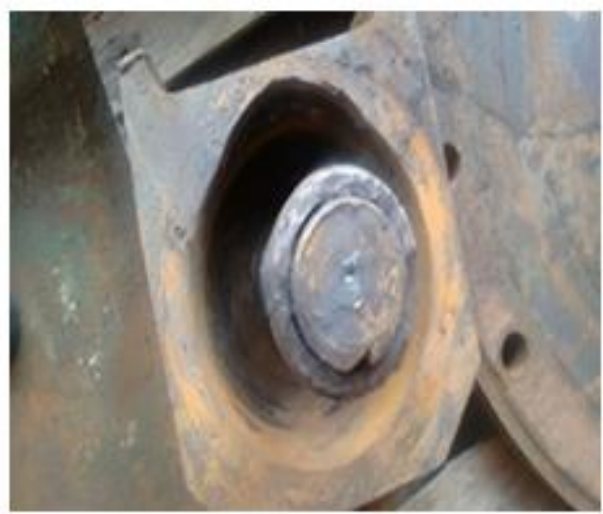

Figura 4 - a) Classificador espiral em operação; b) Mancal submerso danificado. (Curso de Mineração Básico - Vale, 2014)

Foram coletadas em um sistema automatizado as ocorrências de falhas, corretivas e perfil de perdas, e realizado brainstorming das causas das quebras nos classificadores, apresentados na Tabela I.

Tabela I - Brainstorming das causas das quebras nos classificadores. (Pesquisa Direta, 2016)

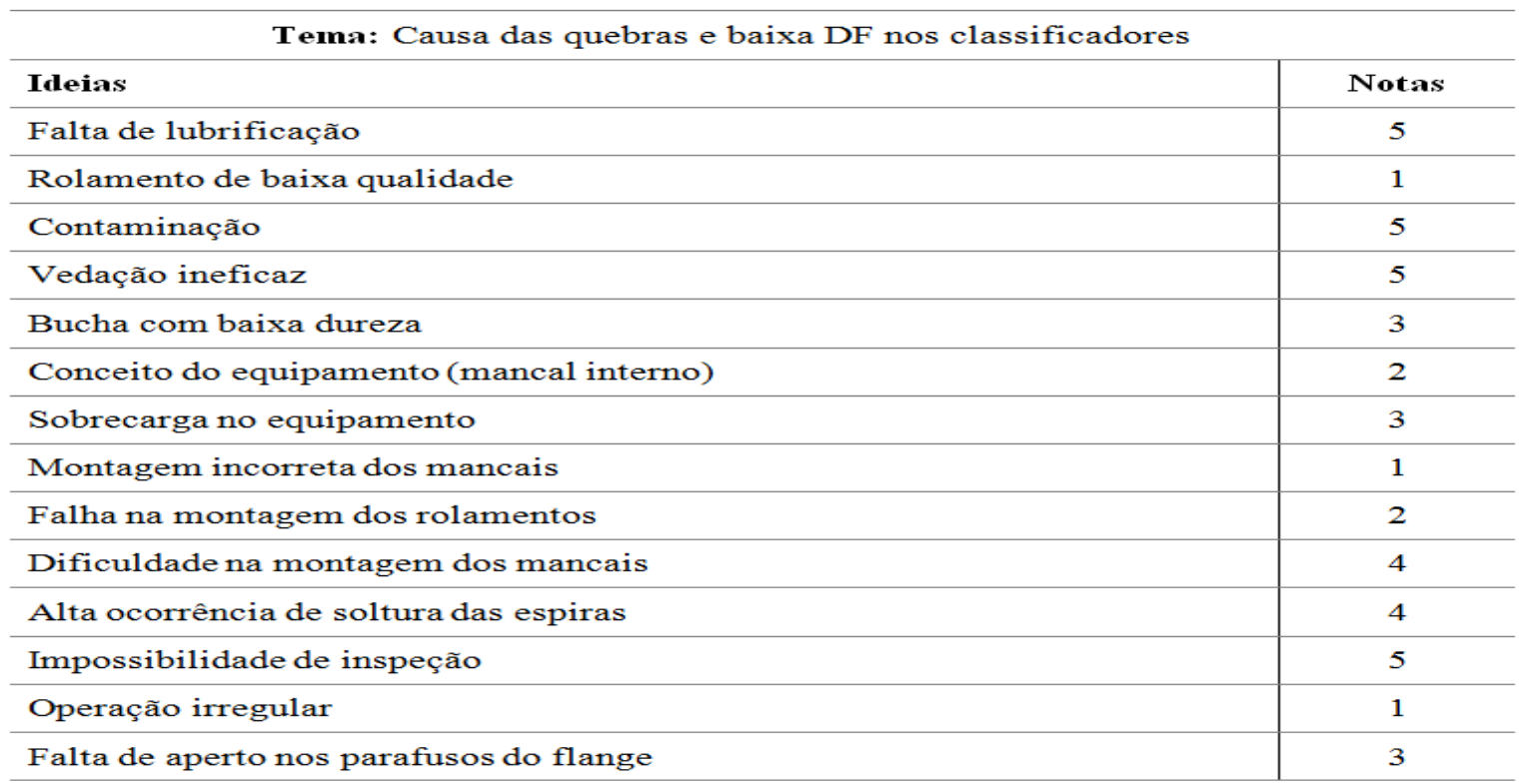

Após a obtenção das causas, apuradas através do brainstorming, foi realizada uma coleta dos dados referentes aos locais das falhas nos classificadores e o tempo para reparo em manutenção corretiva entre o setembro de 2014 a setembro de 2015. Esses dados foram coletados através do sistema de controle informatizado de desempenho dos equipamentos e são apresentados através do diagrama de Pareto na Figura 5. 

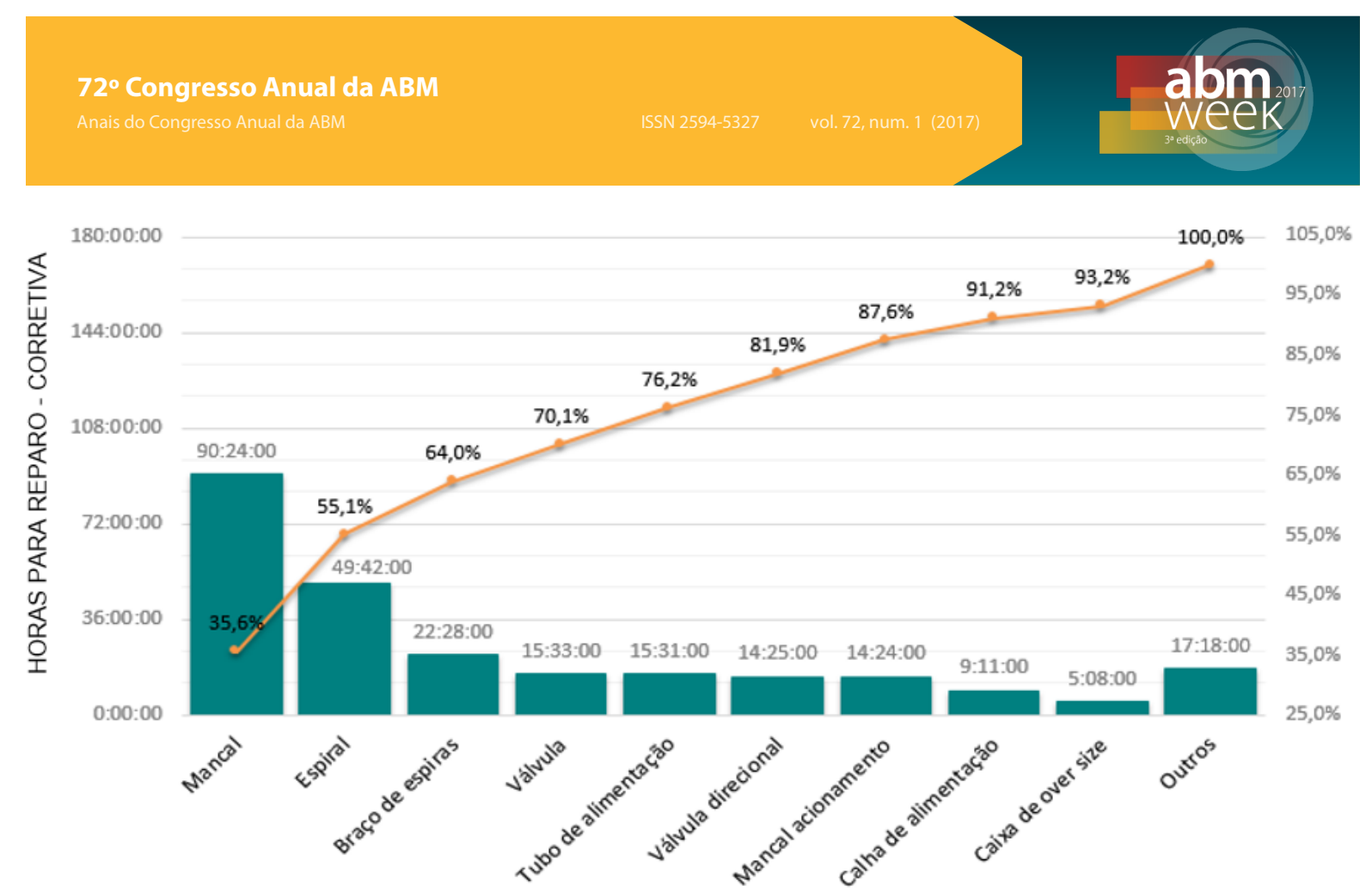

Figura 5 - Pareto dos defeitos nos classificadores entre setembro de 2014 a setembro de 2015.

(Pesquisa Direta, 2016)

As falhas nos mancais e espiras são os principais defeitos apresentados nos equipamentos no período analisado. Foram discutidas algumas propostas mostradas na Tabela II, dentre elas: a substituição do retentor criando a tríplice barreira de proteção conforme Figura $6 \mathrm{a}$, a substituição do rolamento simples por outro com dupla vedação conforme Figura $6 \mathrm{~b}$ e a utilização de espiras revestidas em alto cromo, modular conforme Figura $6 \mathrm{c}$, em substituição às segmentadas em ferro fundido utilizadas. As espiras revestidas em alto cromo e modular, além de reduzir o peso sobre o eixo, possui uma vida útil três vezes maiores que as segmentadas.

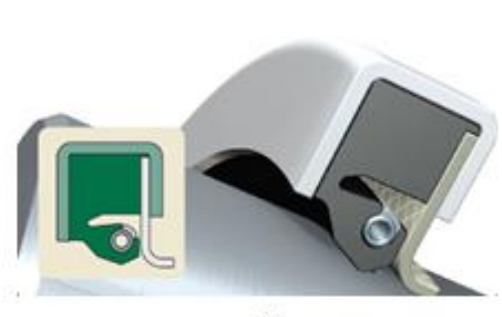

a

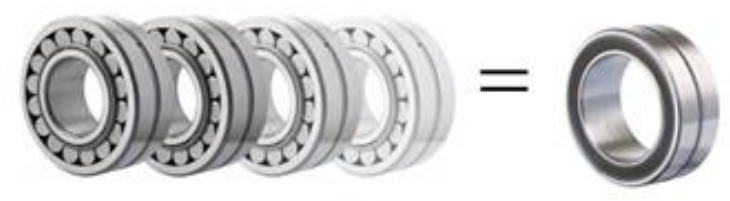

b

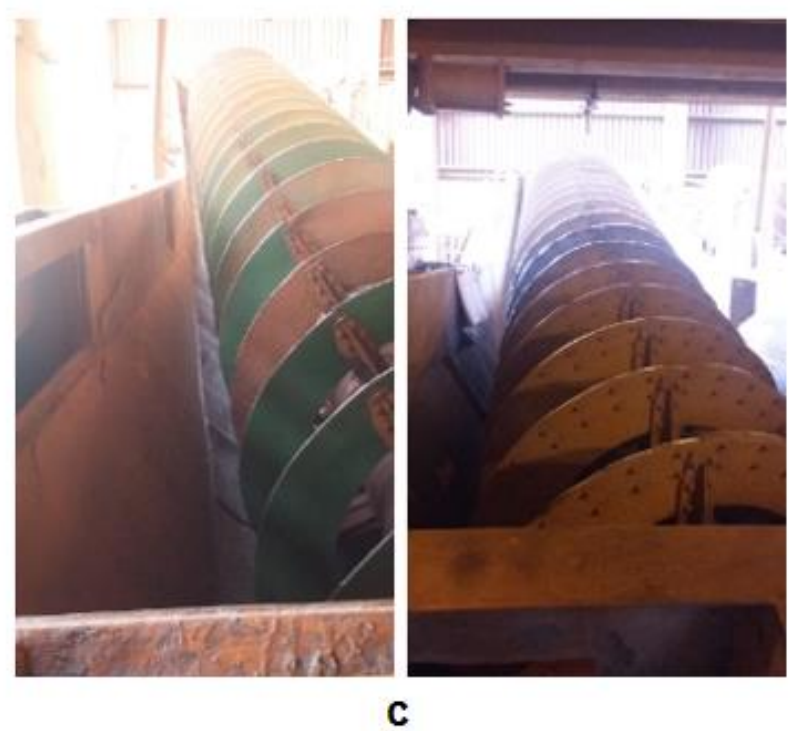

C

Figura 6 - a) Retentores HDSH (SKF - Manual 2015); b) Rolamento vedado (SKF - Manual 2015); c) Espiras revestidas em alto cromo e modular. (Pesquisa Direta, 2016) 
Tabela II - Plano de ação. (Pesquisa Direta, 2016)

\begin{tabular}{|c|c|c|c|c|c|c|}
\hline \multicolumn{7}{|c|}{ Plano de Ação - Mancal Submerso } \\
\hline & O QUE & ONDE & QUANDO & POR QUÊ & COMO & QUEM \\
\hline 1 & $\begin{array}{c}\text { Especificar e } \\
\text { adquirir kits para } \\
\text { mancal submerso } \\
\text { (rolamento e } \\
\text { retentores HDSH) }\end{array}$ & \multirow{8}{*}{ 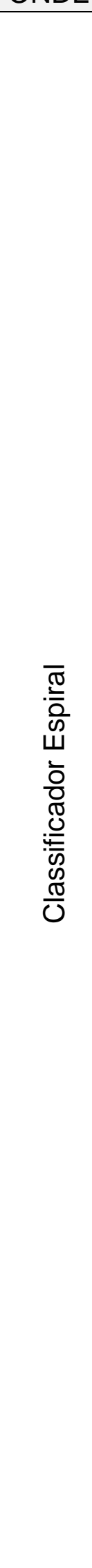 } & Nov/15 & $\begin{array}{c}\text { Substituir os } \\
\text { mancais } \\
\text { submersos }\end{array}$ & $\begin{array}{l}\text { Verificação } \\
\text { junto a SKF e } \\
\text { colocando } \\
\text { requisição no } \\
\text { sistema }\end{array}$ & $\begin{array}{l}\text { Enge- } \\
\text { nharia / } \\
\text { PCM }\end{array}$ \\
\hline 2 & $\begin{array}{l}\text { Atualizar desenho } \\
\text { do mancal } \\
\text { submerso } \\
\text { separando flange e } \\
\text { cabeçote e incluir } \\
\text { rolamentos, } \\
\text { retentores e bucha } \\
\text { especificados }\end{array}$ & & Out/15 & $\begin{array}{l}\text { Facilitar a } \\
\text { compra de } \\
\text { flange e } \\
\text { cabeçote } \\
\text { separado e } \\
\text { mancal via } \\
\text { desenho c/ } \\
\text { os itens }\end{array}$ & $\begin{array}{l}\text { Solicitando a } \\
\text { Engenharia } \\
\text { para que } \\
\text { altere o } \\
\text { desenho }\end{array}$ & $\begin{array}{l}\text { Enge- } \\
\text { nharia }\end{array}$ \\
\hline 3 & $\begin{array}{l}\text { Revisar PRO para } \\
\text { troca do mancal } \\
\text { submerso }\end{array}$ & & Jan/16 & $\begin{array}{l}\text { Evitar } \\
\text { montagem } \\
\text { errada na } \\
\text { área }\end{array}$ & $\begin{array}{l}\text { Verificando } \\
\text { todos os itens/ } \\
\text { acrescentand } \\
\text { o os passos } \\
\text { no PRO }\end{array}$ & $\begin{array}{l}\text { Enge- } \\
\text { nharia }\end{array}$ \\
\hline 4 & $\begin{array}{c}\text { Especificar e } \\
\text { adquirir bucha com } \\
\text { a dureza } \\
\text { necessária para } \\
\text { aplicação nos } \\
\text { mancais submerso }\end{array}$ & & Nov/15 & $\begin{array}{c}\text { Garantir que } \\
\text { a bucha } \\
\text { utilizada seja } \\
\text { a de projeto }\end{array}$ & $\begin{array}{l}\text { Solicitando a } \\
\text { Engenharia }\end{array}$ & $\begin{array}{l}\text { Enge- } \\
\text { nharia }\end{array}$ \\
\hline 5 & $\begin{array}{c}\text { Especificar e } \\
\text { adquirir parafuso } \\
\text { com porca e } \\
\text { contra-porca para } \\
\text { fixação do flange }\end{array}$ & & Out/15 & $\begin{array}{c}\text { Evitar o } \\
\text { afrouxament } \\
\text { o dos } \\
\text { parafusos }\end{array}$ & $\begin{array}{l}\text { Verificando o } \\
\text { parafuso que } \\
\text { tenha a } \\
\text { melhor } \\
\text { aplicação } \\
\text { para o local }\end{array}$ & $\begin{array}{l}\text { Enge- } \\
\text { nharia / } \\
\text { PCM }\end{array}$ \\
\hline 6 & $\begin{array}{c}\text { Manter graxa } \\
\text { especificada pela } \\
\text { Engenharia (optipit) } \\
\text { em estoque }\end{array}$ & & Nov/15 & \begin{tabular}{|c|} 
Graxa \\
especificada \\
pela \\
Engenharia \\
melhor p/ \\
aplicação \\
\end{tabular} & $\begin{array}{l}\text { Colocando } \\
\text { requisição no } \\
\text { sistema }\end{array}$ & PCM \\
\hline 7 & $\begin{array}{l}\text { Especificar e } \\
\text { adquirir espiras } \\
\text { modulares } \\
\text { revestida em alto } \\
\text { cromo }\end{array}$ & & Out/15 & \begin{tabular}{|c|} 
Substituição \\
das espiras \\
segmentada \\
s pela \\
modular \\
revestida
\end{tabular} & $\begin{array}{l}\text { Verificando } \\
\text { junto a } \\
\text { Railroad e } \\
\text { colocando } \\
\text { requisição no } \\
\text { sistema }\end{array}$ & $\begin{array}{l}\text { Enge- } \\
\text { nharia / } \\
\text { PCM }\end{array}$ \\
\hline 8 & $\begin{array}{c}\text { Projetar, } \\
\text { confeccionar e } \\
\text { montar pórtico } \\
\text { conforme projeto } \\
\text { da engenharia. }\end{array}$ & & Out/15 & \begin{tabular}{|c|} 
Para auxiliar \\
na \\
substituição \\
dos mancais \\
submerso
\end{tabular} & $\begin{array}{l}\text { Montagem do } \\
\text { pórtico nos } \\
\text { classificadore } \\
\text { s }\end{array}$ & $\begin{array}{l}\text { Enge- } \\
\text { nharia / } \\
\text { PCM }\end{array}$ \\
\hline
\end{tabular}




\section{RESULTADOS E DISCUSSÃO}

Em virtude da dificuldade de instalação dos mancais submersos, em função do peso, aproximadamente 650 quilos (mancal e flange), foi necessário projetar, fabricar e instalar um pórtico, conforme Figuras $7 \mathrm{a}$ e 7b, para auxiliar na manutenção e substituição dos mancais submersos.
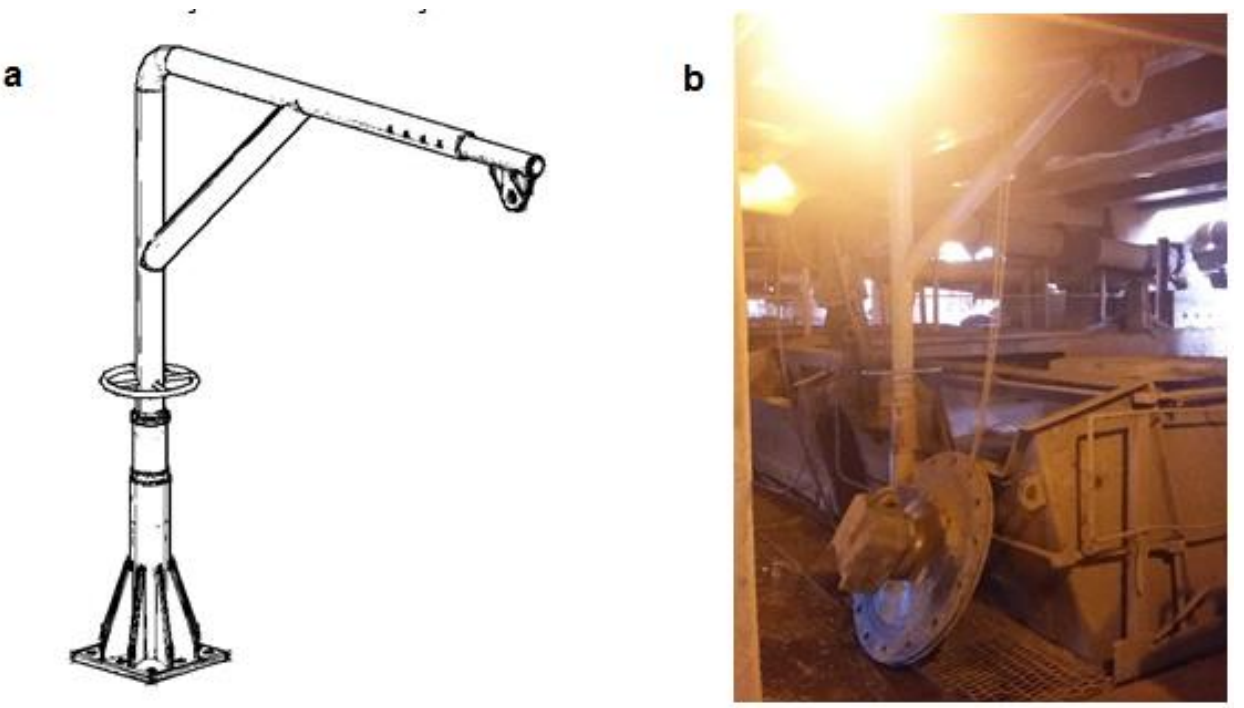

Figura 7 - a) Desenho esquemático do Pórtico desenvolvido; b) Pórtico instalado. (Curso de Mineração Básico - Vale, 2014)

Foi realizado um teste empírico da melhoria, efetivando as ações em uma das linhas dos classificadores. Obteve-se com este procedimento 11 meses de performance do equipamento, índice superior aos 90 dias da manutenção preventiva periódica. Grande parte das espiras dos classificadores foram substituídas pelas espiras revestidas em alto cromo e até o momento não foi constatado nenhum relato de soltura ou quebra destas espiras nos classificadores nos quais se realizou estas substituições.

A Figura 8 mostra o comparativo da DF dos classificadores antes da troca, no período de dezembro de 2014 a novembro de 2015, e após a conclusão e substituições das espiras, entre dezembro de 2015 a novembro de 2016.

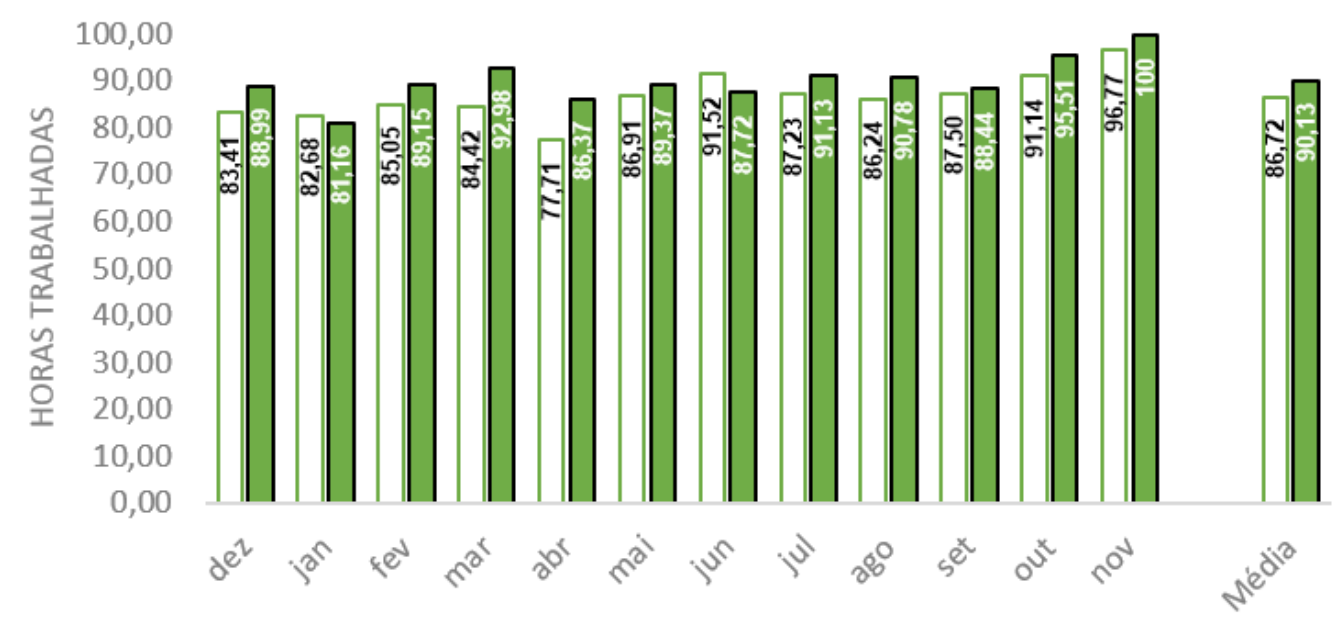

Figura 8 - Comparativo entre DF dos classificadores 2014/15 e 2015/16. (Pesquisa Direta, 2016) 
O resultado tem se mostrado satisfatório, pois a substituição, no conceito original, por preventiva programada que ocorria a cada 90 dias além de eventuais ações corretivas antes deste período, foi satisfatório no teste do mancal após as implementações das espirais revestidas, testadas após 11 meses de operação. A Figura 9 mostra o gráfico de Pareto dos defeitos nos classificadores em 2016, após a troca por espirais revestidas.

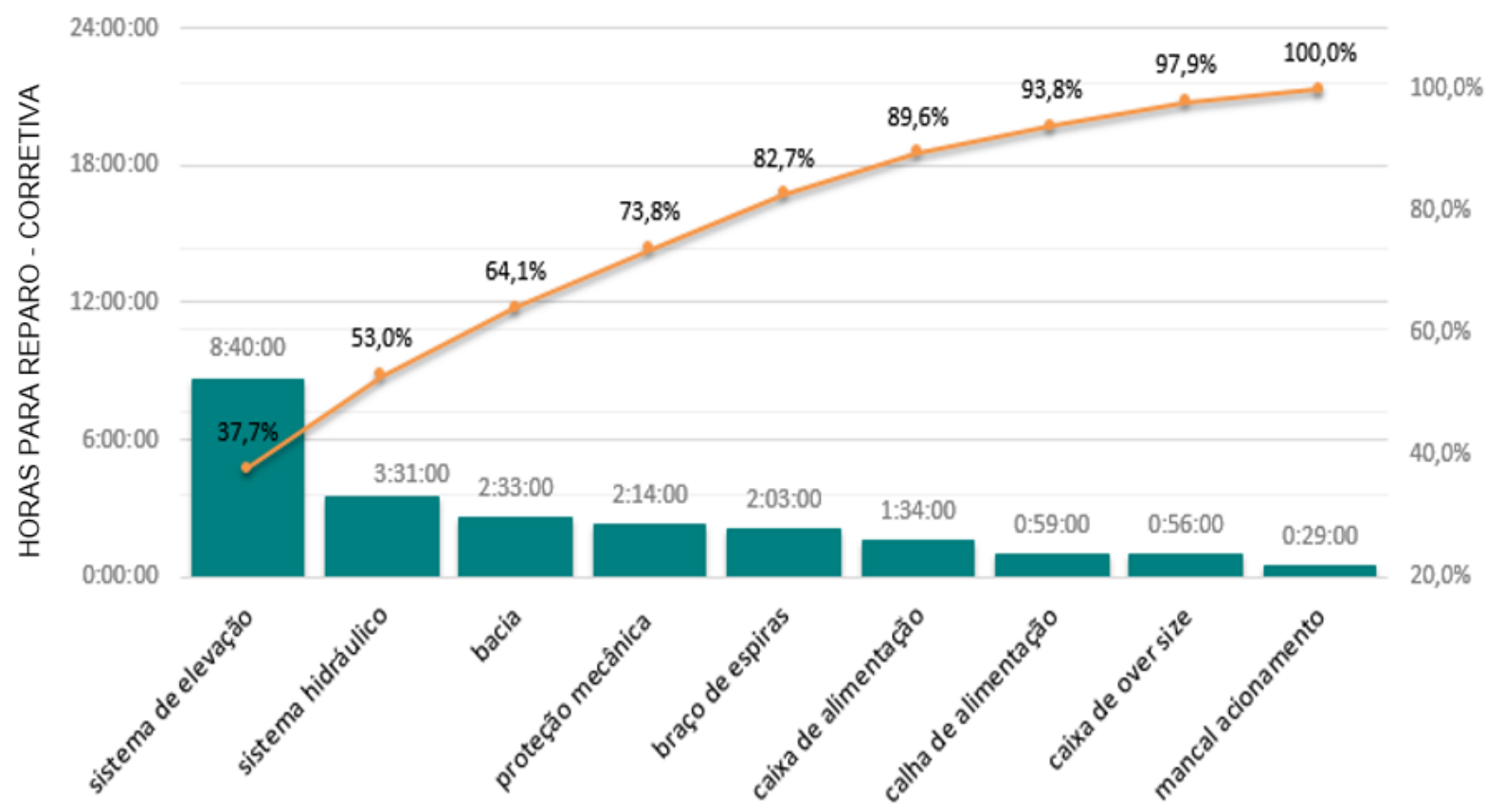

Figura 9 - Pareto dos defeitos nos classificadores 2016. (Pesquisa Direta, 2016)

\section{CONCLUSÕES}

A proposta deste trabalho foi melhorar o desempenho dos classificadores espirais utilizados no processo de beneficiamento de minério de ferro. As trocas realizadas levaram às seguintes conclusões:

1. Comprovou-se a eficácia da melhoria, melhorando significativamente 0 desempenho dos classificadores, evolui-se em três pontos percentuais na disponibilidade física, com uma DF acumulada de 90,13\%, superior aos 86,72 \% média acumulada antes da implementação das melhorias;

2. Diminuiu-se a incidência de manutenção corretiva, evitando quebras dos mancais. Diminuiu-se o tempo para substituição do mancal com a implementação do pórtico para movimentação dos mancais submersos e cilindros de elevação;

3. Aumentou-se a disponibilidade física, porém não houve nenhum relato de substituição preventiva ou corretiva das espiras, os mancais serão substituídos preventivamente a cada 11 meses, tempo muito superior aos 3 meses anteriormente praticado;

4. Neste projeto identificou-se que a quebra do mancal ocorre principalmente pela contaminação e falta de lubrificação e, portanto, a aplicação de rolamento vedado em conjunto com a substituição dos retentores, se mostrou bastante eficaz. Definiu-se o mancal com a tríplice barreira como padrão utilizado definitivamente; 
5. O mancal submerso deixou de ser o componente crítico dos classificadores, as melhorias apresentadas nesta pesquisa têm contribuído significativamente para manter o equipamento mais tempo para operação e com maior confiabilidade;

6. O setor de Engenharia de Manutenção Industrial tem um papel importante no processo de melhoria de desempenho, tanto no gerenciamento da rotina quanto nas melhorias. Este trabalho é um exemplo de sucesso de melhoria desenvolvida pela Engenharia de Manutenção em conjunto com o PCM.

\section{REFERÊNCIAS}

1 ALBUQUERQUE, L. G.; WHELLER, J. E.; VALINE, S. B. Application of high frequency screens in closing grinding circuits $\mathrm{cl}$. In: Encontro Nacional de Tratamento de Minérios e Metalurgia Extrativa, 23. Anais. Gramado: Universidade Federal do Rio Grande do Sul, p.167-173, 2009.

2 ALMEIDA, Paulo Samuel de. Manutenção Mecânica Industrial: Conceitos Básicos e Tecnologia Aplicada. 1a. ed. São Paulo: Érica, 2014.

3 CARRISO, Regina Coeli C.; CORREIRA, Júlio César G. Tratamento de Minérios: Classificação e Peneiramento. 4. ed. Rio de Janeiro: Centro de Tratamento Mineral - Cetem, 2004.

4 CHAVES, Arthur Pinto. Teoria e Prática do Tratamento de Minérios: Bombeamento de polpa e classificação. 4. ed. São Paulo: Oficina de Textos, 2012.

5 Curso de Mineração Básico - Vale, 2014

6 FRANÇA, Silvia Cristiana Alves; LUZ, Adão Benvindo da; SAMPAIO, João Alves. Tratamento de Minérios. 5. ed. Rio de Janeiro: Centro de Tratamento Mineral - Cetem, 2010.

7 METSO, Conceitos Básicos em Processamento de Mineiras, 2. ed. 2012.

8 NORMA REGULADORA DE MINERAÇÃO. NRM-18 (Beneficiamento). Ministério das Minas e Energia. Disponível em: http://www.dnpmpe.gov.br/Legisla/nrm_18.htm acesso em 24 set. 2016.

9 PEREIRA, Mário Jorge. Engenharia de Manutenção: Teoria e Prática. 2. ed. Rio de Janeiro: Ciência Moderna, 2011.

10 SKF, Manual de Rolamentos autocompensadores de rolos vedados, 2015.

11 VARELA, J. Critérios de seleção de britadores aplicados ao processamento mineral. In: XXIV ENTMME, Salvador, 2011. p.384-391. 